1 Universidade Federal de Santa Maria (UFSM) Santa Maria (RS), Brasil. fabianafaiolla@gmail.com

\section{Atividades educativas sobre armazenamento e descarte correto de medicamentos: relato de experiência com público infantil}

\author{
Educational activities about storage and correct disposal of \\ medicines: experience report with children audience
}

Fabiana de Paula Faiolla', Annelise Alcântara Altieri Ribeiro', Carlos Eduardo de Souza Brener $\mathbf{1}$ Henrique Veit', Valéria Maria Limberger Bayer', Verginia Margareth Possatti Rocha', Edi Franciele Ries $^{1}$

DOI: $10.1590 / 0103-1104201912021$

RESUMO A conscientização do público infantil sobre uso racional e práticas adequadas relacionadas a medicamentos incentiva a transformação a partir da educação infantil e impulsiona a multiplicação desse conhecimento nas famílias. Nessa perspectiva, o objetivo deste trabalho é relatar a experiência de ações de conscientização com público infantil visando a orientar e divulgar a forma correta de armazenamento e descarte de medicamentos realizada por um programa de extensão de uma instituição de ensino superior. As atividades foram realizadas em duas escolas públicas rurais de um município do interior do Rio Grande do Sul, envolvendo alunos da pré-escola ao $8^{\circ}$ ano do ensino fundamental. Elas foram planejadas e organizadas pelos extensionistas, que conduziram a abordagem das temáticas por meio de perguntas orais, orientação dialogada, com apoio de recurso audiovisual e quiz de assimilação de conteúdo. $\mathrm{O}$ público, de aproximadamente 125 pessoas, demonstrou aceitação e interesse pela temática, participando com relatos iniciais de práticas adotadas em suas residências e respondendo às perguntas no final das atividades. Verificaram-se tanto aprendizagem das informações pelas crianças quanto motivação para as práticas adequadas e multiplicação de conhecimento. As atividades educativas mostraram-se positivas e poderão ser subsídios para ações de educação em saúde, em outras localidades.

PALAVRAS-CHAVE Educação infantil. Conscientização. Saúde pública.

ABSTRACT Children awareness on the rational use and appropriate medicines-related practices encourages transformation through early childhood education and boosts the multiplication of such knowledge in families. In this perspective, the aim of this work is to report the experience of actions awareness with children aiming to guide and divulge the correct way of storage and disposal of medicines carried out by an extension program of an institution of higher education. The activities were carried out in two rural public schools of a municipality of the interior of Rio Grande do Sul, involving pre-school students to the 8th year of elementary school. They were planned and organized by extensionists, who led the approach to the topics through oral questions, negotiated orientation, with support of audiovisual resource and content assimilation quiz. The public, of approximately 125 people, showed acceptance and interest on the subject, participating 
with initial reports of practices adopted in their residences and answering the quiz questions at the end of the activities. The learning of children's information and the motivation for appropriate practices and the multiplication of knowledge have been verified. The educational activities were positive and could be subsidies for actions of health education, in other locations.

KEYWORDS Child rearing: Awareness. Public health.

\section{Introdução}

A Revolução Técnico-científico-informacional, que teve início na segunda metade do século $\mathrm{XX}$, desencadeou uma série de descobertas e evoluções no campo tecnológico, incluindo as áreas química e biomédica. Em vista disso, a indústria farmacêutica pôde disponibilizar ampla variedade de fármacos com acesso facilitado à população em geral, de modo a desencadear o que Barros ${ }^{\mathbf{1}}$ denomina 'sociedade medicalizada', em que a busca de saúde e bem-estar se relaciona diretamente com o uso de medicamentos, resultando no seu consumo exacerbado.

Assim, a existência de farmácias caseiras é uma realidade que deve ser debatida. Uma discussão iniciada por Tourinho et al. ${ }^{2}$ dispõe que os medicamentos mantidos nos domicílios representam maior risco para agravos à saúde devido ao consumo irracional, à automedicação, com possibilidade de desencadear intoxicações, especialmente em crianças. Exposto que a população por vezes mantém uma diversidade de medicamentos guardados em discordância com as recomendações de armazenamento ${ }^{3}$, tornam-se essenciais atividades que abordem os cuidados especiais necessários para se manter a eficácia dos princípios ativos e a segurança no uso do fármaco 4 .

$\mathrm{O}$ acesso infantil a estoques caseiros de medicamento foi averiguado por Schwingel et $a^{3}{ }^{3}$, que descreveram a ausência de embalagens, bulas e informações de validade dos medicamentos armazenados, sob condições errôneas de exposição à luz, à umidade e ao calor, e que, quando descartados, eram tratados de maneira incorreta. Por esta razão, as ações educativas se destinaram ao público infantil, como forma de prevenir a manipulação de medicamentos pelos menores, como também de guiar seus pais e responsáveis para o armazenamento e o descarte ambientalmente corretos. No entanto, essas são iniciativas ainda escassas em municípios do interior do Rio Grande do Sul (RS) e em unidades de saúde distritais.

O ambiente escolar é apontado como local ideal para o compartilhamento de informações e conhecimentos sobre assuntos relevantes de cunho coletivo, como saúde pessoal e cuidados com o meio ambiente. Segundo Angelim et al. ${ }^{5}$, trabalhar as representações sociais de um determinado tema em um ambiente escolar, a partir da análise do conhecimento social compartilhado e na visão do senso comum dessa população, é indispensável na formação de cidadãos para a vida em sociedade.

Nesse contexto, é necessário considerar a relevância da conscientização do público infantil como potencial multiplicador, bem como a expansão de ações de educação em saúde para armazenamento e descarte de medicamentos. Isso corrobora o observado por Holek ${ }^{6}$ e Schunemann e Rosa ${ }^{7}$, os quais apontam que a formação de cidadãos responsáveis se inicia na escola, onde não somente o conhecimento é difundido, mas, também, os valores culturais determinantes na atuação perante o meio e o ensino político. Adicionalmente, Menezes ${ }^{8}$ aponta a importância do público infantil como 
influência para os pais, responsáveis e amigos, pois as crianças tomam a conduta de interagir com os demais acerca das suas atividades desenvolvidas e do seu papel na sociedade, disseminando informações e conhecimentos.

A abordagem do público infantil por meio das atividades educativas relatadas neste trabalho objetivou a orientação e a divulgação da forma correta de armazenamento e descarte de medicamentos, que muitas vezes é desconhecida pela população adulta, com intuito de conscientização, promoção da saúde e multiplicação de conhecimento. Nesse sentido, este relato tem o propósito de descrever a experiência das ações realizadas por um programa de extensão de uma instituição de ensino superior.

\section{Métodos}

A experiência relatada foi resultado de atividades educativas em duas escolas de ensino público infantil e fundamental de um município do interior do RS sobre práticas adequadas relacionadas a medicamentos. As ações de conscientização foram realizadas por acadêmicos bolsistas e voluntários dos cursos de medicina, farmácia e odontologia, de programa de extensão de uma universidade federal, entre junho e julho de 2018.

As atividades educativas foram planejadas e organizadas pelo grupo extensionista em reuniões semanais. Nelas, foi escolhido o perfil do público-alvo e, a partir daí, foi definida a abordagem mais adequada para conduzir as ações, de forma dinâmica e eficiente.

Foram selecionadas duas escolas de distritos do município. A escola 1, composta por alunos do $5^{\circ}$ ao $8^{\circ}$ ano do ensino fundamental, e a escola 2 , formada por alunos da pré-escola ao $5^{\circ}$ ano do ensino fundamental, ambas públicas e localizadas em áreas rurais. Além dos alunos, público-alvo principal, participaram das atividades os professores, a direção escolar e os demais funcionários presentes.

As ações ocorreram em uma tarde letiva e foram estruturadas em cinco momentos: apresentação do grupo, perguntas orais diagnósticas, orientação dialogada com utilização de slides sobre armazenamento e descarte ambientalmente correto de medicamentos e conscientização do público, assimilação do conteúdo abordado através de um quiz e encerramento das atividades pelo grupo.

Inicialmente, houve a apresentação dos universitários e do programa de extensão, evidenciando a missão acerca da conscientização da população sobre o armazenamento e o descarte correto de medicamentos. Em seguida, foram realizadas perguntas orais, a fim de: a) conhecer os espectadores; b) saber o que eles consideravam correto sobre o tema; e c) como suas famílias armazenavam e descartavam medicamentos em suas casas. Segundo o preconizado por Guarda et al. ${ }^{9}$, o diálogo é uma ferramenta insubstituível de aproximação com a criança, pois através dele entramos em seu mundo. Depois de conhecido o público em questão e seus hábitos, passou-se à extensão dos conhecimentos acadêmicos à comunidade.

A abordagem sobre armazenamento e descarte ambientalmente correto de medicamentos foi realizada por meio de uma orientação dialogada, dinâmica e bem-humorada. A comunidade escolar assistiu à apresentação de slides sobre como armazenar corretamente os medicamentos em suas residências e descartar os que estiverem vencidos ou em desuso, compartilhando as vivências domiciliares. Em seguida, mostrou-se como não se deve armazenar e descartar, e, por último, como fazê-lo de modo adequado. Foram utilizados slides na apresentação, os quais continham muitas imagens e figuras coloridas, ao mesmo tempo instrutivas, deixando a apresentação adequada para motivar o aprendizado pelas crianças. O uso de figuras, além de facilitar o entendimento, chama a atenção do público e desperta o interesse ${ }^{10}$. Adicionalmente, a exposição teve propósito de ensinar como transformar uma caixa simples de papelão, 
de calçados, por exemplo, em um local adequado para armazenamento, com a finalidade de as crianças levarem esse conhecimento para suas residências e confeccionarem um local adequado para armazenamento doméstico dos medicamentos, juntamente com seus pais.

Foi formulado um quiz como instrumento para fixação do conteúdo pelos alunos e para percepção do aprendizado pelo público-alvo. O instrumento foi composto de questões de diferentes níveis de dificuldade, algumas utilizando exemplos de situações, outras objetivas e outras, ainda, que conduzissem a respostas incorretas. Em decorrência das faixas etárias diferenciadas nas ações, o vocabulário das perguntas foi adaptado para fácil compreensão das crianças. $\mathrm{Na}$ escola 2, as questões foram estratificadas de acordo com as turmas devido à amplitude de idade do público-alvo. Houve distribuição de brindes aos alunos que acertaram primeiro as perguntas. A escolha desse momento de descontração e brincadeira justifica-se ao saber que o ato de brincar tem fundamental importância no processo de aprendizagem da criança enquanto ser humano, pois, em conjunto com a diversão, acontece a formação da assimilação de conhecimentos da criança, que será levada para sua vida futura"1. Além do quiz, na escola 1, o grupo sorteou entre os professores uma caixa confeccionada para o armazenamento doméstico dos medicamentos.

As atividades foram encerradas com distribuição de doces e material educativo validado, sobre armazenamento e descarte correto, aos presentes. Na escola 2, também foram distribuídos balões coloridos para as crianças e as cartilhas informativas foram entregues aos professores, que se responsabilizaram a enviar aos pais. A distribuição de material educativo adequado é fundamental no processo de conscientização da população, pois as informações disponíveis sobre os temas são escassas e muitas vezes incompletas ${ }^{10}$. Por último, o grupo fez o registro fotográfico dos eventos.

\section{Resultados e discussão}

As atividades educativas contemplaram um público de 125 pessoas, sendo 60 e 65 pessoas na Escola 1 e na Escola 2, respectivamente. $\mathrm{O}$ resultado alcançado foi positivo, pois, além da boa aceitação, do interesse e do comprometimento do público com o assunto, a mudança de postura dos espectadores ficou evidente ao longo da realização do evento, ressaltando a importância da conscientização nessa fase do desenvolvimento humano.

Nas diretrizes curriculares nacionais para a educação infantil, do Ministério da Educação, de 2010, a criança é definida como:

Sujeito histórico e de direitos que, nas interações, relações e práticas cotidianas que vivencia, constrói sua identidade pessoal e coletiva, brinca, imagina, fantasia, deseja, aprende, observa, experimenta, narra, questiona e constrói sentidos sobre a natureza e a sociedade, produzindo cultura'12(15).

Em virtude dessa definição, a educação infantil é um momento oportuno para o desenvolvimento de saberes que serão levados por toda a vida da criança, como o consumo consciente, o cuidado com a saúde e a valorização e o respeito ao meio ambiente, pois esse é um dos primeiros espaços de contato com outras pessoas e de interação com a sociedade. Ademais, de acordo com Szymanski (2010), citado por Moura ${ }^{13}$, todas as pessoas com as quais a criança se relaciona na escola, meio institucional, tornam-se corresponsáveis pelo seu processo de aprendizagem, socialização e constituição. Por essa razão, é essencial iniciar um trabalho de conscientização já na educação infantil. Assim, desde a infância, elas são estimuladas a tomar decisões conscientes e compartilhar responsabilidades ${ }^{\mathbf{1 4}}$.

O momento de abertura das ações, do qual os alunos das escolas participaram e em que contaram como acontece em suas casas e como seus pais manuseiam os medicamentos, foi importante para assimilar as informações 
trazidas por eles, além de se tratar de uma estratégia utilizada para deixar os alunos mais desinibidos e a ocasião mais dinâmica. Para Torok ${ }^{15}$, a abertura deve ser 'explosiva', para captar a atenção do grupo e render sucesso da atividade comunicativa. Com isso, as crianças, principalmente na escola 2, participaram ativamente da apresentação e tornaram a experiência muito mais enriquecedora e bem aproveitada por todos.

A sinceridade das crianças em relatar as práticas inadequadas com medicamentos, que, por vezes, presenciaram com os pais em suas casas, além do seu papel na fiscalização dessas ações, chamaram a atenção do grupo. Nesse momento, ao analisar a 'denúncia' das crianças, percebeu-se que, em muitas das residências, os pais tinham atitudes equivocadas com relação ao uso e ao manuseio dos medicamentos, fato também relatado por Anunciação et al. ${ }^{16}$.

Nos relatos de diagnóstico, o público infantil afirmou que os medicamentos, em suas residências, encontram-se fora do seu alcance e que são sempre seus pais que os manejam e os oferecem a eles, quando necessário, refletindo a conscientização dos responsáveis frente aos riscos do acesso das crianças aos medicamentos. Contradizendo essas narrações, um estudo de Tourinho et al. ${ }^{2}$, que analisou as condições das farmácias domiciliares no interior do estado de São Paulo, verificou que a maioria dos estoques de medicamentos está armazenada em caixas de papelão em locais de fácil acesso às crianças menores de 6 anos da região. Essa divergência no cuidado com o armazenamento pode estar relacionada a diferenças de hábitos e culturas quando comparadas diferentes regiões brasileiras. Dados do Sistema Nacional de Informações TóxicoFarmacológicas (Sinitox), referentes ao ano de 2016, apontaram os medicamentos como principais agentes de intoxicação em seres humanos no Brasil, representando cerca de $36 \%$ dos casos de intoxicação. Cerca de 33\% dos acidentes ocorrem com crianças menores de 4 anos ${ }^{17}$. Portanto, o local escolhido para o armazenamento de medicamentos em domicílios é de extrema importância para se minimizar riscos de intoxicação.

A grande maioria relatou, no início da ação, como lugar correto para o descarte de medicamentos, o lixo doméstico, e, realmente, acreditavam que esse era o local adequado. Apesar de as consequências ambientais desses fármacos descartados incorretamente ainda não serem bem conhecidas, segundo Ponezi et al. (2008), citado por Eickhoff et al. ${ }^{18}$, sabe-se que eles são eventuais responsáveis por efeitos adversos à saúde humana, animal e de organismos aquáticos, principalmente quando são descartados erroneamente e acabam alcançando rede de esgotos e águas. Alguns fármacos merecem atenção especial, como os antibióticos, que podem selecionar ou induzir resistência bacteriana; os estrogênios, que podem agir no sistema reprodutivo de organismos aquáticos e levar à feminização dos peixes machos; e os medicamentos usados em quimioterapia, antineoplásicos e imunossupressores, que são potenciais agentes mutagênicos ${ }^{18}$.

Na orientação dialogada, foi discutida a importância dos cuidados com os medicamentos armazenados em casa. Nesse sentido, algumas informações foram repassadas: a) manter os medicamentos na embalagem original para garantir sua conservação e identificação; b) guardar os medicamentos em locais frescos, longe do calor, da luz e da umidade, portanto, não devem ser armazenados no banheiro ou na cozinha; c) manter os medicamentos que precisam ser armazenados em geladeira nas prateleiras, e não na porta ou no congelador; d) armazená-los longe do alcance das crianças; e) sempre observar as recomendações do fabricante e se as características do produto continuam as mesmas após abertura das embalagens; f) checar periodicamente o local de armazenamento dos medicamentos em domicílio, principalmente para verificar as validades dos mesmos; e, por último, g) medicamentos vencidos e que restarem ao final do tratamento devem ser descartados de forma correta ${ }^{19}$.

O descarte adequado também foi alvo da ação, que orientou a fazê-lo em farmácias ou 
unidades de saúde da região leste do município, as quais participam do Programa de conscientização da população e recolhimento de medicamentos em desuso nas unidades de saúde na região leste de Santa Maria (RS) e possuem pontos de coleta de medicamentos vencidos ou em desuso. Os alunos das escolas-alvo das ações assistiram atenciosamente às explicações fornecidas pelos extensionistas.

Com relação à orientação para o descarte nas farmácias, a fim de preservar a saúde pública e a qualidade do meio ambiente, os estabelecimentos comerciais podem participar do programa de coleta de medicamentos a serem descartados pela comunidade, mas não são obrigados por lei nacional a recolher esses produtos $^{20}$. No entanto, no município de Santa Maria (RS), a Lei ${ }^{0} 5.786$, de 28 de agosto de 201321, "estabelece procedimentos a serem adotados para o descarte de medicamentos vencidos e de suas embalagens no Município de Santa Maria", ficando os estabelecimentos obrigados a receber e acondicionar os medicamentos vencidos e suas respectivas embalagens, bem como a providenciar-lhes destino ambientalmente adequado.

Durante a conversa, os alunos ficaram atentos, pouco dispersos e demonstraram interesse pelo tema, principalmente na escola 2 . Ao comparar as perguntas diagnósticas da situação inicial com as do quiz realizado no final da atividade, foi perceptível uma mudança na compreensão da temática, no tocante à valorização do assunto e ao aprendizado do público-alvo. Se, no início, foram relatadas várias situações inadequadas, consideradas pelo público-alvo corretas, no final, após a conversa, raramente alguma criança respondia de forma incorreta às perguntas. Situação similar foi observada por Anunciação et al. ${ }^{16}$, que salientaram a internalização do aprendizado através dos relatos obtidos das crianças sobre o descarte e a preocupação delas com o meio ambiente.

Na escola 2, um aluno mencionou que não era correto guardar medicamentos na cozinha, pois ficava perto do fogão à lenha.
Essa informação desencadeou uma discussão sobre a importância do cuidado com a temperatura do local do armazenamento. Ela é o fator ambiental mais importante a se considerar no armazenamento de medicamentos, influenciando diretamente em sua estabilidade, pois a velocidade de degradação do fármaco é diretamente proporcional ao aumento da temperatura22.

Na escola 1, respondendo a uma pergunta do quiz que induzia à resposta incorreta, uma criança corrigiu sobre a forma de descarte dizendo que não é correto misturá-los com água e jogar na pia, prática doméstica comum relatada para descarte de medicamento. De acordo com Aquino, Brandt e Chernicharo ${ }^{23}$, apenas um pequeno grupo de fármacos é satisfatoriamente removido dos esgotos domésticos pelas técnicas convencionais utilizadas nas Estações de Tratamento de Esgoto (ETE). Assim, essas substâncias podem chegar à água de abastecimento humano em quantidades não previstas e se tornar um risco potencial para a saúde humana. A presença desses elementos nas águas levadas para as Estações de Tratamento de Água (ETA) é, hoje, um desafio para essas companhias ${ }^{\mathbf{2 4}}$.

Um ponto relevante foi a percepção do grupo quanto à necessidade de adaptação da linguagem e do vocabulário para trabalhar com o público infantil, que se mostrou uma estratégia indispensável para a realização de uma efetiva conscientização. Conforme sugere Torok ${ }^{\mathbf{1 5}}$, não se deve tratar o público infantojuvenil de maneira inferior, pois, caso eles percebam, o repasse de informações pode ser prejudicado. A linguagem deve ser clara e concisa, conter informação, mas também ser criativa e rica. Além disso, para se obter o êxito esperado na atividade, ela precisa ser bem explicada e segura ${ }^{15}$.

Acrescenta-se, também, a importância da distribuição de brindes no quiz, realizada no final da atividade, principalmente na escola 1, para captar a atenção e motivar o aprendizado das crianças. De acordo com Alcará e Guimarães ${ }^{25}$, alunos motivados participam 
de tarefas mais entusiasmados e demonstram disposição para novos desafios, pois buscam sempre novos conhecimentos e oportunidades. Sendo assim, a aprendizagem ocorre mediante motivação, e, a partir daí, o aluno busca atribuir significado ao assunto aprendido ${ }^{26}$. Além disso, as metas e os objetivos que os alunos propõem para o seu futuro são um determinante motivacional24.

Alguns obstáculos foram relatados pelo grupo extensionista após a experiência na escola 1. Os universitários relataram dificuldade inicial em chamar a atenção das crianças para o assunto, ter uma linguagem acessível e adequada a elas e a dificuldade de monitorar as crianças no quiz. Anunciação et al. ${ }^{16}$ relataram a dificuldade na captação da atenção do público infantil e a importância de estudar e definir estratégias adequadas à transmissão do objetivo e da mensagem da atividade e participação ativa das crianças.
Essas limitações foram analisadas nas reuniões do grupo e adaptadas como estratégia de ação no evento da escola 2. Primeiramente, foram citadas e discutidas todas as dificuldades encontradas no evento da primeira escola. Em seguida, as percepções da situação nortearam as adequações e a construção do plano com estratégias metodológicas de ação, focadas no público da escola 2. Dessa forma, na segunda escola, as perguntas do quiz foram estratificadas e direcionadas para os alunos de níveis escolares diferentes, e somente as crianças do nível associado à questão poderiam responder, para que, assim, todas tivessem a chance de participação. Como resultado, os universitários tiveram atenção especial dos alunos e participação mais ativa das crianças, ao compararem com a experiência anterior. A abordagem de temática do quiz (quadro 1) poderá ser utilizada em outras localidades e/ou adaptada para diferentes públicos, contribuindo para as práticas de educação em saúde.

Quadro 1. Modelo de quiz aplicado para assimilação de conteúdo sobre armazenamento e descarte correto de medicamentos

1. Por que não é indicado guardar medicamentos no banheiro?

2. A cozinha é um local prático, cheio de prateleiras e gavetas para guardar muitos objetos. Sabendo disso: é indicado guardar medicamentos nos armários da cozinha, junto com os materiais de limpeza?

3. Alguns medicamentos devem ser guardados na geladeira. Sabendo disso: qual é o melhor lugar dentro dela para armazená-los?

4. Qual o cômodo da casa mais indicado para guardar os medicamentos?

5. Os medicamentos devem ser guardados em local fechado, ao qual as crianças e animais domésticos não tenham acesso. Sabendo disso: é adequado guardar os medicamentos em uma caixa em cima do guarda-roupa do quarto?

6. Carros geralmente são muito seguros, não têm umidade e possuem muitos compartimentos para guardar objetos. Sabendo disso: é indicado armazenar medicamentos dentro de veículos?

7. Por que é importante não tirar o medicamento da embalagem original?

8. Ficar atento à validade do medicamento é muito importante. Existem medicamentos que podem ser tomados mesmo vencidos?

9. O que devemos fazer com os medicamentos, vencidos ou que não são usados, guardados em nossa casa? 
Quadro 1. (cont.)

10. Sofia precisa tomar comprimidos de um medicamento controlado todos os dias, por isso acha mais prático deixar as caixas do medicamento sobre a bancada da cozinha para não se esquecer da medicação. Ela está correta?

11. Carlos precisa viajar e está com muitas caixas de seu medicamento controlado em casa, mas ouviu dizer que medicamentos não podem ficar dentro do carro. Ele deve comprar novas caixas do medicamento quando chegar ao seu destino?

12. Para medicamentos com indicação de armazenamento na geladeira, a recomendação correta é deixá-los nas portas perto dos ovos, já que os ovos também precisam ser protegidos, correto?

13. Para descartar o medicamento e evitar que outras pessoas usem de forma errada, ele não deve ser jogado no lixo, mas dissolvido na pia, ou no vaso sanitário. Essa atitude está correta?

14. Renata tem muitos medicamentos em casa e, para ter mais espaço, decidiu que vai jogar as caixas dos medicamentos no lixo. Ela está correta? Qual a melhor forma de aliviar esse espaço?

15. É bom ter medicamentos em casa, por isso, é correto sempre guardar medicamentos em desuso para uma próxima doença, correto?

16. Crianças e animais não têm consciência sobre o uso dos medicamentos, por isso, não é preciso se preocupar com o local de armazenamento, já que não vão mexer em nada. Essa atitude está correta?

17. Cláudia está com muita dor de cabeça e encontrou um analgésico vencido há uma semana. Por ser pouco tempo ela pode tomar sem ter medo dessa atitude causar problemas à sua saúde?

18. Eduardo tem uma caixa de medicamentos guardada em seu armário de roupas, geralmente não tem tantos em desuso porque olha a caixinha sempre que possível. Ele está correto?

19. Sônia sente tonturas e vive dizendo ao esposo que não se deve guardar a caixa de medicamentos em cima do armário, já que ela precisa subir em cadeiras ou escadas para conseguir pegar, e isso pode causar acidentes. Ela está correta ou apenas exagerando?

20. Qual a melhor maneira de armazenar os medicamentos em casa?

Fonte: Elaboração própria.

No final das atividades, foram distribuídos, para o público infantil, na escola 1, materiais educativos sobre armazenamento e descarte ambientalmente correto de medicamentos. Também foi solicitado a eles que repassassem as informações e o material aos pais ou responsáveis. Na escola 2 , foi solicitado aos professores que colocassem o material na mochila dos alunos. A promoção e a educação em saúde em ambiente escolar revelam-se, então, como importantes estratégias para conscientização de toda a comunidade envolvida através de sua repercussão, na medida em que as crianças adquirem valores fundamentais para a vida, entre os quais estão os vinculados à saúde ${ }^{13}$.

\section{Considerações finais}

O uso racional de um medicamento está relacionado a adequadas condições de armazenamento e descarte. Essas práticas são realizadas de maneira inadequada por grande parte dos cidadãos por falta de informação e divulgação dos danos causados ao meio ambiente e à saúde pública. Uma estratégia utilizada para solucionar o problema é a disseminação de informações por meio do público infantil.

Ao analisar os resultados dessas ações educativas, percebeu-se que as crianças aprenderam as informações, tornaram-se 
multiplicadoras de conhecimento e fiscais das ações da família em suas residências. Dessa forma, os objetivos das atividades foram alcançados e essa experiência ratifica os princípios conceituais dos projetos de extensão, na medida em que estabelecem um verdadeiro elo entre a universidade e a sociedade.

Um ponto importante a ser destacado, percebido a partir dos relatos da comunidade escolar, é a particularidade dessa região em relação a outras, até mesmo do próprio município. Essa constatação incentiva a realização de novas ações de divulgação do conhecimento sobre o assunto em outros locais, fortalecendo ainda mais a missão extensionista dos universitários.

Adicionalmente, essas atividades proporcionaram experiência enriquecedora e desafiadora para os extensionistas, aproximando a academia da comunidade ao colocar em prática conceitos técnicos e teóricos.

A extensão proporciona expansão do espaço de aprendizagem dos acadêmicos, viabilizando o compartilhamento de conhecimento e desenvolvendo competência para atividade interprofissional, humana, autônoma e ética.

Portanto, espera-se a geração de impacto nas famílias, que receberão as informações sobre o assunto, através das crianças, e poderão dar continuidade à transmissão de conhecimento na comunidade, além do impacto gerado nos universitários, que servirão de subsídio para a criação de novos encontros e trabalhos em prol da promoção da saúde coletiva e do bem-estar ambiental.

\section{Colaboradores}

Faiolla FP (0000-0001-6535-4385)* contribuiu para a concepção, planejamento, coleta dos dados, redação, revisão e aprovação da versão final do manuscrito. Ribeiro AAA (0000-0002-7643-1240)* contribuiu para a concepção, planejamento, coleta dos dados, apresentou sugestões importantes incorporadas ao trabalho, revisão crítica do conteúdo e aprovação da versão final do manuscrito. Brener CES (00000003-2327-2044)* contribuiu para a coleta dos dados, apresentou sugestões importantes incorporadas ao trabalho, revisão crítica do conteúdo e aprovação da versão final do manuscrito. Veit H (0000-00022408-8735)* contribuiu para a coleta dos dados, apresentou sugestões importantes incorporadas ao trabalho, revisão crítica do conteúdo e aprovação da versão final do manuscrito. Bayer VML (0000-00026731-4835)* contribuiu para a orientação do trabalho, apresentou sugestões importantes incorporadas ao trabalho e aprovação da versão final do manuscrito. Rocha VMP (0000-0002-8062-095X)* contribuiu para a orientação do trabalho, apresentou sugestões importantes incorporadas ao trabalho e aprovação da versão final do manuscrito. Ries EF (0000-0001-6688-2913)* contribuiu para a concepção, orientação e aprovação da versão final do manuscrito. 


\section{Referências}

1. Barros JAC. Pensando o processo saúde doença: a que responde o modelo biomédico?. Saúde soc. [internet]. 2002 [acesso em 2018 ago 24]; 11(1):67-84. Disponível em: http://www.scielo.br/scielo.php?script=sci_ arttext\&pid=S0104-12902002000100008\&lng=en.

2. Tourinho FSV, Bucaretchi F, Stephan C, et al. Farmácias domiciliares e sua relação com a automedicação em crianças e adolescentes. J. Pediatr. (Rio J.) [internet]. 2008 [acesso em 2018 ago 24]; 84(5):416-422. Disponível em: http://www.scielo.br/scielo.php?script=sci_arttext $\&$ pid $=$ S0021$-75572008000600007 \& \operatorname{lng}=\mathrm{en}$.

3. Schwingel D, Souza J, Simonetti E, et al. Farmácia caseira x uso racional de medicamentos. Rev. Cad. Pedagógico [internet]. 2015 [acesso em 2018 ago 25]; 12(3):117-130. Disponível em: http://www.univates.br/ revistas/index.php/cadped/article/view/973/961.

4. Figueiredo MC, Kothe V, Vieira L, et al. Armazenagem e descarte de medicamentos: uma questão de educação e saúde. In: Anais do $3^{\circ}$ Congresso Internacional de Tecnologias para o Meio Ambiente; 2012 abr 25-27; Bento Gonçalves. Rio Grande do Sul: Universidade de Caxias do Sul; 2012. p. 1-8.

5. Angelim RCM, Pereira VMAO, Freire DA, et al. Representações sociais de estudantes de escolas públicas sobre as pessoas que vivem com HIV/Aids. Saúde debate [internet]. 2017 [acesso em 2018 ago 25]; 41(112):221-229. Disponível em: http://www. scielo.br/scielo.php?script=sci_arttext\&pid=S0103$-11042017000100221 \& \operatorname{lng}=\mathrm{pt}$.

6. Holek MT. Como a prática da conscientização do meio ambiente é importante no processo da educação infantil [monografia] [internet]. Medianeira: Universidade Tecnológica Federal do Paraná; 2014. 28 p. [acesso em 2018 ago 24]. Disponível em: http://repositorio.roca.utfpr.edu.br/jspui/bitstream/1/4203/1/ MD_ENSCIE_IV_2014_75.pdf.

7. Schunemann DR, Rosa MB. Conscientização ambiental na educação infantil. REMOA/UFSM [internet]. 2010 [acesso em 2018 ago 24]; 1(1):122-132. Disponível em: https://periodicos.ufsm.br/remoa/article/view/2295.

8. Menezes CMVMC. Educação ambiental: a criança como um agente multiplicador [monografia] [internet]. São Caetano do Sul: Centro Universitário do Instituto Mauá de Tecnologia; 2012. 46 p. [acesso em 2018 ago 24]. Disponível em: https://maua.br/files/ monografias/completo-educacao-ambiental-crianca-como-agente-multiplicador-280830.pdf.

9. Guarda GN, Nicaretta T, Rodrigues T, et al. A roda de conversa como metodologia educativa: o diálogo e o brincar oportunizando o protagonismo infantil na sala de aula. In: Anais do $13^{\circ}$ Congresso Nacional de Educação: EDUCERE; 2017 ago 28-31; Curitiba. Paraná; 2017. p. 12886-12889.

10. Jesus PR, Zucco BS, Oliveira DM, et al. Descarte de medicamentos: contextualização e desenvolvimento de material educativo. In: Torres VLG, organizadora. Princípios e Fundamentos das Ciências da Saúde 2. Belo Horizonte: Atena; 2018. p. 61-76.

11. Souza, CF. A importância do brincar e do aprender das crianças na educação infantil [monografia] [internet]. Rondônia: Faculdade de Rolim de Moura; 2018. 15 p. [acesso em 2018 nov 30]. Disponível em: https://facsaopaulo.edu.br/wp-content/uploads/sites/16/2018/05/edl/3.pdf.

12. Brasil. Ministério da Educação. Secretaria de Educação Básica. Diretrizes curriculares nacionais para a educação infantil. Brasília, DF: MEC; SEB; 2010.

13. Moura KR. Abordagem da saúde da criança na educação infantil: percepção das educadoras. [dissertação] [internet]. São Carlos: Universidade Federal de São Carlos; 2012. 110 p. [acesso em 2018 ago 22]. Disponível em: https://repositorio.ufscar.br/bitstream/ handle/ufscar/3257/4981.pdf.

14. Link DJ, Araújo LEB, Rampelotto EM, et al. Conscientização ambiental com alunos da educação infantil da escola de ensino fundamental Kinderwelt de Agu- 
do - RS. REMOA/UFSM [internet]. 2012 [acesso em 2018 ago 18]; 6(6):1305-1311. Disponível em: https:// periodicos.ufsm.br/remoa/article/view/4642.

15. Torok S. Falar de ciência para crianças: algumas dicas. In: Massarani L, editor. Ciência e criança: a divulgação científica para o público infanto juvenil. Rio de Janeiro: Fiocruz, 2008. p. 50-55.

16. Anunciação CC, Dal Mora T, Dutra SC, et al. A percepção de uma comunidade escolar sobre o uso e descarte de medicamentos: uma proposta educacional possível. CATAVENTOS - Revista de Extensão da Universidade de Cruz Alta [internet]. 2010 [acesso em 2018 ago 15]; 2(1):1-12. Disponível em: http://200.19.0.178/ index.php/Cataventos/article/view/446.

17. Fundação Oswaldo Cruz. Sistema nacional de informações tóxico-farmacológicas. Casos registrados de intoxicação humana por agente tóxico e faixa etária. Brasil, 2016. Rio de Janeiro: Fiocruz; 2016.

18. Eickhoff P, Heineck I, Seixas LJ. Gerenciamento e destinação final de medicamentos: uma discussão sobre o problema. Rev. Bras. Farm. [internet]. 2009 [acesso em 2018 ago 17]; 90(1):64-68. Disponível em: http://www.scielo.br/scielo. php?script $=$ sci_nlinks $\&$ ref $=000115 \&$ pid $=$ S1413$-8123201300030003400006 \& \operatorname{lng}=$ pt.

19. Pinto VB. Armazenamento e distribuição: o medicamento também merece cuidados. In: Carvalho FD, Wannmacher L, editores. Uso Racional de Medicamentos: fundamentação em condutas terapêuticas e nos macroprocessos da Assistência Farmacêutica. Brasília, DF: OPAS/OMS; 2016. p. 1-7.

20. Agência Nacional de Vigilância Sanitária. Resolução da Diretoria Colegiada ${ }^{\circ}$ 44, de 17 de agosto de 2009 [internet]. Dispõe sobre Boas Práticas Farmacêuticas para o controle sanitário do funcionamento, da dispensação e da comercialização de produtos e da prestação de serviços farmacêuticos em farmácias e drogarias e dá outras providências. 17 ago 2009 [acesso em $2018 \mathrm{dez}$ 3]; Disponível em: https://www20.anvisa.gov.br/segurancadopaciente/index.php/legislacao/item/rdc-44-2009.
21. Santa Maria. Lei $\mathrm{n}^{0} 5.786$, de 28 de agosto de 2013 [internet]. Estabelece procedimentos a serem adotados para o descarte de medicamentos vencidos e de suas embalagens no Município de Santa Maria. 28 ago 2013. [acesso em $2018 \mathrm{dez}$ 3]; Disponível em: http://pmsantamaria.rs.publicidademunicipal.com. br/Pages/Home.aspx.

22. Santos VLP. Estabilidade e tempo de vida útil de fármacos e medicamentos [dissertação] [internet]. Porto: Universidade Fernando Pessoa; 2012. 83 p. [acesso 2018 ago 17]. Disponível em: https://bdigital.ufp.pt/ bitstream/10284/3755/3/PPG_VanessaSantos.pdf.

23. Aquino SF, Brandt EMF, Chernicharo CAL. Remoção de fármacos e desreguladores endócrinos em estações de tratamento de esgoto: revisão da literatura. Eng. Sanit. Ambient. [internet]. 2013 [acesso em 2018 nov 30]; 18(3):2187-204. Disponível em: http://www.scielo.br/scielo.php?pid=S1413$-41522013000300187 \&$ script=sci_abstract\&tlng=pt.

24. Borges RM, Minillo A, Lemos EGM, et al. Uso de filtros de carvão ativado granular associado a microrganismos para remoção de fármacos no tratamento de água de abastecimento. Eng. Sanit. Ambient. [internet]. 2016 [acesso 2018 ago 18]; 21(4):709-720. Disponível em: http://www.scielo.br/scielo.php?script=sci abstract\&pid=S1413-41522016000400709\&lng=pt.

25. Alcará AR, Guimarães SER. A Instrumentalidade como uma Estratégia Motivacional. Psicol. esc. educ. [internet]. 2007 [acesso em 2018 ago 22]; 11(1):177-178. Disponível em: http://pepsic.bvsalud.org/scielo.php?script=sci_arttext\&pid=S1413$-85572007000100019 \& \operatorname{lng}=\mathrm{pt} \& \ln \mathrm{l}=\mathrm{pt}$.

26. Lourenço AA, Paiva MOA. A motivação escolar e o processo de aprendizagem. Ciênc. cogn. [internet]. 2010 [acesso 2018 ago 22]; 15(2):132-141. Disponível em: http://pepsic. bvsalud.org/scielo.php?script=sci_arttext\&pid=S1806$-58212010000200012 \& \operatorname{lng}=$ pt\&tlng=pt.

Recebido em 30/08/2018

Aprovado em 07/12/2018

Conflito de interesses: inexistente

Suporte financeiro: não houve 